\title{
In response to "Calculation of indirect costs of associated with postoperative caregiver absences after pediatric tonsil surgery"
}

\author{
Gunnhildur Gudnadottir $^{1}$ (1) . J. Stalfors ${ }^{1} \cdot$ J. Hellgren ${ }^{1}$
}

Received: 8 January 2018 / Accepted: 10 January 2018 / Published online: 19 January 2018

c) Springer-Verlag GmbH Germany, part of Springer Nature 2018

We agree that the time with analgesic treatment after surgery is possibly an unreliable measure of the time the child stays home after surgery. That is why, we, in our article "Indirect costs related to caregivers' absence from work after paediatric tonsil surgery", also compared the time the caregivers received temporary parental benefits in the first month after surgery. Both methods showed similar absenteeism after tonsil surgery, and caregivers stayed home longer after tonsillectomy than tonsillotomy resulting in higher costs [1]. The difference was clearly significant, both statistically and clinically.

Regrowth of tonsillar tissue is a possible cause for additional surgery later on. This was addressed in our article as a problem that can affect the total absenteeism costs, as the risk of tonsillar regrowth is larger after tonsillotomy than tonsillectomy [2,3]. Our study was not designed to explore the magnitude of this effect but this is an interesting area for further research.

There are many factors that may affect the postoperative pain and resultant recovery time after paediatric tonsil surgery and the methods mentioned in the letter "Calculation of indirect costs of associated with postoperative caregiver absences after pediatric tonsil surgery" are interesting subjects for further research. This is, however, beyond the scope of the present study, as we were limited to the previously existing information in the database used and did not have access to such detailed information on different surgical methods, local anesthesia and analgesics used. The effects of each of these factors should preferably be researched in a prospective randomized trial.

\section{Compliance with ethical standards}

Conflict of interest Gunnhildur Gudnadottir declares that she has no conflict of interest. Joacim Stalfors declares that he has no conflict of interest. Johan Hellgren declares that he has no conflict of interest.

Ethical approval This article does not contain any studies with human participants or animals performed by any of the authors.

\section{References}

1. Gudnadottir G, Tennvall GR, Stalfors J et al (2017) Indirect costs related to caregivers' absence from work after paediatric tonsil surgery. Eur Arch Otorhinolaryngol 274:2629-2636

2. Odhagen E, Sunnergren O, Hemlin C et al (2016) Risk of reoperation after tonsillotomy versus tonsillectomy: a population-based cohort study. Eur Arch Otorhinolaryngol 273:3263-3268

3. Windfuhr JP, Savva K, Dahm JD et al (2015) Tonsillotomy: facts and fiction. Eur Arch Otorhinolaryngol 272:949-969

This reply refers to the comment available at https://doi. org/10.1007/s00405-017-4779-1.

Gunnhildur Gudnadottir

gunhildur.gudnadottir@vgregion.se

1 Department of Otorhinolaryngology, Sahlgrenska University

Hospital, Sahlgrenska Academy, Gothenburg University,

Gothenburg, Sweden 